\title{
A PRODUÇÃO DO CONHECIMENTO SOBRE A POLIITICA EDUCACIONAL NO BRASIL: UM OLHAR A PARTIR DA AN PED*
}

\author{
Janete M aria Lins de Azevedo** \\ M Árcia Ângela Aguiar ***
}

\begin{abstract}
RESU M 0: Este texto contém resultados de uma pesquisa que anal isou as características e as tendências da produção do conhecimento sobrea política educacional no Brasil, tomando como base empírica a produção apresentadano G rupo deT rabalho daAnped "Estado ePolíticaE ducacional", no período de 1993 a 2000. Tendo como pressupostos que a legitimação dessa produção, assim como as suas tendências predominantes resultam deum embate deten dências/olhares equeos trabal hos traduzem relações efetivas entre os pesquisadores, organizações sociais envolvidas ea realidade analisada, as autorasfazem um resgatehistórico da origem eda trajetória desteG T para, em seguida, apresentar - quantitativa equalitativamente- um quadro doseixos temáticos esubtemá ticos que têm prevalecido no período estudado. À luz das análises empreendidas, concluem destacando alcances elimites da institucionalização desteGT e, portanto, do campo do conhecimento focalizado.

Palavras-chave: Política educacional; Brasil; Anped; Grupo deT rabalho Estado ePolíticaEducacional; C aracterísticas da produção científica; Revisão de produção.
\end{abstract}

\section{Considerações iniciais}

0 presente texto intenta uma reflexão sobre características etendências das investigações vinculadas ao campo de produção intelectual

\footnotetext{
* Pesquisa desenvolvida com o apoio do CN Pq.

* D outora em Ciências Sociais pela Unicamp, pesquisadora do CN Pq e coordenadora do Programa de Pós-G raduação em Educação da U niversidade F ederal de Pernambuco (U FPE). E-mail: jazevedo@br.inter.net

*** D outora em Educação pela USP, coordenadora do GT "Estado e política educacional" da Anped e professora do Programa de Pós-Graduação em Educação da UFPE. E-mail: marciaangela@zipmail.com.br
} 
(Bourdieu, 1989) dos saberes sobre a política educacional no Brasil, a partir da análise dos trabalhos apresentados nas oito últimas reuniões anuais da Associação $\mathrm{N}$ acional de Pós-G raduação e Pesquisa em Educação (Anped) no âmbito do seu Grupo de Trabalho (GT) "Estado e Política Educacional". ${ }^{1}$

A opção por analisarmos a produção que converge para um GT da Anped inspirou-se nas formulações de Bourdieu (1976), quando ele trata da estrutura de um campo científico e dos processos de reconhecimento e legitimidade conferidos àqueles que dele participam.

Para este autor, o tipo de luta científico-política pela legitimidade depende da estrutura que se forja no interior de cada campo de saber, que é também condicionada por fatores a ele externos. N este contexto, em todos os campos são encontrados os dominantes, cujas posições advêm do reconhecimento do montante do capital científico de que são detentores, e os dominados, ou novatos, que necessitam ter reconhecida a importância do seu capital, das suas potencialidades, bem como da sua posição atual e potencial no campo. Entretanto, éo resultado do jogo de forças nele presentes que vai permitir, ou não, 0 avanço significativo da produção do conhecimento de que o campo seocupa (Bourdieu, 1976).

0 ato, pois, de nos debruçarmos sobre a produção de um grupo de trabalho integrante da estrutura organizacional da Anped, teve por base o significado desta Associação para a comunidade acadêmica. Com efeito, a Anped é uma das principais entidades científicas do campo da educação no Brasil (senão a principal) e, como tal, vem desempenhando um importante papel legitimador do conhecimento produzido sobre a educação. A legitimação processa-se por meio de uma série de ritos e práticas, desenvolvidos nos interstícios de tempo de suas reuniões anuais, que pode efetivar-se, ou não, quando os trabal hos são publicizados nos $\mathrm{GTs}^{2}{ }^{2}$ os quais representam uma peça fundamental da engrenagem alimentadora da Associação.

$\mathrm{N}$ a medida em quetivemos subjacente essa perspectiva, éoportuno compartilharmos algumas das preocupações que orientaram as análises aqui apresentadas. Em primeiro lugar, ao termos focalizado a produção que tem convergido para o GT, em certa medida, isso significou tomálo, também, como um objeto de estudo. 0 bjeto este cuja construção e existência são forjadas no bojo de outras instituições que com eleinteragem e lhe conferem vida, por meio das práticas sociais de distintos atores.

Em conseqüência, buscamos, inicialmente, voltar o olhar para o próprio processo de institucionalização do $\mathrm{GT}$, visto que a sua trajetória 
e o seu papel de aglutinador/difusor do conhecimento que se produz sobre a área são alimentados pelo que ocorre em outros espaços institucionais. D e fato, 0 alimento advém, sobretudo, das práticas sociais que configuram a produção do conhecimento nos Programas de Pós-G raduação em Educação associadas à Anped, particularmente daqueles que se ocupam da área temática que Ihe é concernente.

$\mathrm{N}$ esse sentido, $0 \mathrm{GT}$, como uma das células vitais da Anped, representa também uma parcela significativa do espaço de discussão e de publicização dos resultados da investigação científica da área, cumprindo, como parte dessa associação, a função de legitimação daquilo que produz a comunidade acadêmica que com que ela interage. A legitimação, como demonstra Santos (1995), na atual conjuntura mostra-se, mais do que nunca, imprescindível para que esta comunidade sobreviva enquanto tal, dada a crise que perpassa e ameaça as instituições voltadas para a produção do saber, particularmente as universidades públicas. Sendo assim, escolhas, ordenações, seleções e demais atos que configuram a existência e as formas de organização assumidas pelo GT , direta ou indiretamente, trazem as marcas das relações de força e de poder próprias de um espaço que atua no sentido de realização daquela função de legitimação.

Além disso, se, de um lado, a sua identidade reflete a cadeia das relações acadêmico-institucionais que ele abriga, de outro, é também fortemente influenciada pelas especificidades conferidas pela sua própria área temática: os condicionantes advindos da própria política educacional e, portanto, da ação do Estado (Azevedo, 1997). É esta ação que se encarrega, em última instância, de fazer emergir os múltiplos objetos em que se transmuda a sua temática e dos quais vão se ocupar os pesquisadores que para ele convergem.

Em conseqüência, a sua trajetória e existência não se descuram dos condicionantes advindos dos novos padrões de regulação que os Estados nacionais estão assumindo no final deste século, em decorrência, por seu turno, do surgimento dos novos padrões societais que o movimento da acumulação capitalista está impondo.

$\mathrm{N}$ esse contexto, como sabemos, ao mesmo tempo em que a educação tem ganho uma especial centralidade - devido ao fato de a ciência estar sendo progressivamente convertida em força produtiva assi ste-se, local emundialmente, às sucessivas ações do Estado no sentido da reformulação dos sistemas de ensino. Essas ações, por sua vez, têm se caracterizado pela agilidade de sua decisão eimplementação, distanciando, ainda mais, o fosso que separa o tempo da produção dos saberes advindos 
das investigações, do tempo político das decisões sobre a política educacional (Paiva, 1998). Fato este que é agravado pelos parâmetros que estão regendo tais decisões, já que tendem a distanciar a política educacional do atendimento dos direitos de cidadania, colocando-a na direção do aumento dos níveis de exploração e de exclusão que caracterizam a atual fase do desenvolvimento.

A estemovimento, pesquisas e pesquisadores não estão incólumes. A perplexidade, a busca angustiada de novos conceitos e categorias que permitam apreender a dinâmica do real - num campo de conhecimento que ainda não possui uma tradição de institucionalidade - o recurso à denúncia, a intensa politização dos estudos, são práticas que só podem ser compreendidas quando relacionadas ao contexto social mais amplo em que se inserem e com o qual se articulam.

É oportuno, neste ponto, lembrarmos especificidades presentes no campo de produção intelectual dos saberes sobre a educação, particularmente quando estamos a vivenciar um momento de crise e de transição paradigmática. N esse sentido, não esqueçamos que a educação, na qualidade de uma prática social, tem nas chamadas Ciências da Educação os referenciais que alimentam a produção do conhecimento que the confere identidade como campo científico autônomo. E as Ciências da Educação, por seu turno, constituem-se a partir das contribuições advindas de outros campos, particularmente dos da área das Ciências Sociais e H umanas, o que tem significado, por um lado, uma configuração marcadamente multidisciplinar e, por outro, a existência de uma tensão quase permanente entre a justaposição e a integração desses saberes na identidade epistemológica do campo aqui em destaque (Brandão \& Bonamino, 1994).

U ma das con seqüências dessa condição éa posição pouco destacável que ocupa a educação na hierarquia social dos campos científicos. De fato, sua posição é ainda menos privilegiada do que a dos campos pertinentes às Ciências Sociais e H umanas que o alimentam. Em particular, no momento atual, este quadro tem se agravado, dada a prevalência do pen samento tecnicista/utilitarista, que vai transformando a ciência numa força produtiva, "submetendo-a ao utopi smo automático da tecnologia", sem permitir qualquer privilegiamento do humanismo e em que pouco se tem avançado na "invenção social de um novo conhecimento emancipatório" (Santos, 2000, p. 117).

A partir das referências acima apresentadas, a construção das nossas reflexões desenvolveu-se de acordo com os procedimentos descritos a 
seguir. T endo por base uma análise documental, procuramos resgatar a trajetória do GT "Estado e Política Educacional" no contexto da Anped. $\mathrm{N}$ orteadas por aspectos desta trajetória, realizamos a análise de conteúdo dos 88 resumos dos trabalhos selecionados para apresentação nas oito últimas reuniões, no intuito de obter uma visão panorâmica da problemática em estudo. Em seguida, procedemos à análise de conteúdo dos textos integrais dos 21 trabalhos apresentados na 22 2 - R eunião Anual (1999) e na 23á (ocorrida no ano 2000). ${ }^{3}$ Esta última estratégia visou construir um maior grau de aprofundamento das reflexões, mesmo que tenha limites de ordem espaço-temporal. ${ }^{4}$

À luz da problemática educacional contemporânea, tentamos identificar veios teóricos que vêm secundando essa produção, a sua classificação temático-conceitual e, ainda, a sua articulação com as principais questões da educação que, na atualidade, estão sendo social mente problematizadas (Azevedo, 1997) pelosmais distintos atores e tendências e que têm sido alvo da ação do Estado, de acordo com as novas formas de regulação das políticas sociais. D esse modo, procuramos fazer um rastreamento sobre o "estado" das investigações na área temática e, portanto, do campo social que vem se constituindo a partir destas práticas, como um primeiro passo na direção de futuros estudos que possam traçar o "estado da arte" das pesquisas e do conhecimento pertinentes.

\section{Brevehistórico do G rupo deT rabalho "Estado ePolítica Educacional"}

No contexto da Anped, o surgimento do GT, em certa medida, vai se dar num momento privilegiado, quando esta entidade já havia feito a opção por ser primordial menteum fórum de discussão, socialização e publicização da pesquisa educacional produzida no País. Tal opção viabilizou-se com o forte concurso dos grupos de trabalho, e teve início no momento em que eles passaram a ser considerados como base principal de sua estrutura organizativa e, portanto, como o veículo que iria pôr em prática a nova prioridade.

Essa redefinição, dentre outras coisas, objetivou tornar a Anped mais autônoma em relação ao Estado, tendo em vista que a sua criação, nos anos 70, atendera a uma sugestão dos órgãos governamentais, levandoa a se caracterizar, principalmente, como um fórum de discussão dos Programas de Pós-G raduação, e a que só tangencialmente se ocupasse da pesquisa. ${ }^{5}$ Conforme testemunho de um dos atores deste processo: 
Fomos percebendo, assim, que as reuniões da Anped não poderiam ser apenas a reunião desses programas. $\mathrm{H}$ avia uma efervescência e uma inquietação intelectual de pesquisas mais amplas. Parece que aí surgiram os GTs - mais específicos e mais ricos. (Anped, 1986a, p. 4)

0 ano em que a mudança se concretiza é o de 1981, período em que estava em vigência o último governo da ditadura militar, o do presidente Figueiredo, e o projeto da abertura política se disseminara pela sociedade civil, envolvendo o campo educacional e a Anped.

$\mathrm{N}$ aquele momento, um grupo de associados conseguira fazer valer a proposta de tentar desvinculá-la das diretrizes da política educacional do Estado, o que tomou corpo durante a 4a Reunião: o novo estatuto, então aprovado, incorporou os G T s à sua estrutura organizacional e a entidade, desde então, deixou de ser apenas uma associação de programas de pós-graduação para abranger também os pesquisadores.

A Anped definiu então os GT s e isto dependeu fundamentalmente de quem esteve presente àquela reunião. A eleição da presidência e da secretaria geral significou o enfrentamento de dois grupos: daquel es que queriam refletir sobre a educação na sociedade, em termos mais amplos, e daqueles que estavam no antigo esquema, em virtude dos cursos de pós-graduação. 0 s G T sterminaram representando a vitória da primeira tendência [...]. A nosso ver, não era mais possível continuar discutindo a organização de programas de pós-graduação. Eranecessário extrapolar para questões mai s voltadas à pesquisa, possibilitando um avanço na área. (Anped, 1986a, p. 5)

O s sete primeiros grupos de trabalho, também criados durante a $4^{a}$ R eunião Anual, ${ }^{6}$ deveriam se enquadrar nas definições então tomadas, as quais passavam a considerar os GT s como o locus para discussão e troca de opiniões sobre resultados de pesquisas e de experiências metodológicas, para a seleção de problemas relevantes e para intercâmbios de informações bibliográficas e de estudos e trabalhos (idem, 1986a). Conforme registram os seus boletins, nas reuniões subseqüentes vários outros gruposforam sendo criados ea meta principal, desde então, passou a ser o fortalecimento dos GTs, como meio de garantir a dimensão científica da associação.

É nestenovo contexto que começaram as mobilizações para a criação do nosso GT, cuja institucionalização só se concretizou cinco anos após aquelas mudanças, precisamente em 1986, quando da $9^{a}$ Reunião. Seu prenúncio, entretanto, aparece pela primeira vez em 1984, quando se registra que esteve em pauta a discussão de um G rupo de T rabalho sobre "Política, Administração e Planejamento da Educação", nome pelo qual 
será denominado nos dois primeiros anos de sua existência (idem, 1986c, p. 19).

Em certa medida, a sua institucionalização beneficiou-se da experiência que a Anped havia acumulado durante os anos anteriores. A contínua avaliação do modo de organização adotado em 1981, de um lado, indicava que os grupos formados a partir de eixos temáticos mostravam uma melhor perfomance do que os estruturados segundo os níveis de ensino. D eoutro, levara a proposições de redefinição dos GTs, quando da $9^{2}$ Reunião, deliberando-se que fizessem um balanço do seu funcionamento desde a sua criação, destacassem a produção relativa à temática nos últimos anos, definissem o núcleo básico e a coordenação, traçassem um esquema de funcionamento e elaborassem sua proposta de ação (idem, 1986b, p. 5).

Essas orientações puderam ser incorporadas ao seu processo de estruturação, com a vantagem de não ser um meio de correção de práticas anteriores. U ma decorrên cia concreta daquelas redefinições teve materialidade na elaboração da sua proposta de trabalho, cuja aprovação e implementação ocorreram durante a 10² Reunião, no ano de 1987.

$\mathrm{N}$ este documento ficou estabelecido que o GT iria congregar estudos cujo eixo central fossem as relações entre Estado, sociedade e educação no Brasil, devendo se configurar como "campo de aprofundamento da análise dos padrões de intervenção do Estado; dos seus mecanismos e formas de gestão das políticas públicas, em especial das chamadas políticas sociais, entre as quais se inscreve a política educacional."

D e acordo com esta perspectiva, foram eleitas como focos deinteresse as pesquisas que abordassem as

estruturas de poder e a política educacional; as transformações tecnológicas e suas implicações no setor; gastos públicos com a educação e as formas de articulação entre as diversas esferas jurídico-administrativas na definição e na condução das políticas educacionais. (Anped,1993, p. 54)

Como podemos observar, houve um privilégio de abordagens macroestruturais da política educacional, o que refletia uma recusa das orientações tecnicistas que predominaram no período da ditadura militar e que ainda se faziam presentes em cursos de pós-graduação cujas áreas de concentração abrangiam o Planejamento ea Administração daEducação. $\mathrm{N}$ ão por acaso, ainda durante a $10^{\mathrm{a}}$ Reunião, o nome do GT foi trocado, quando passou a ser chamado de "Estado e Política Educacional 
no Brasil", indicando que o processo de sua criação envolveu embates entre orientações teórico-políticas divergentes, eque saíra vitoriosa a tendência explicitada em sua proposta. N ão obstante, essa mesma proposta também serviu para acomodar e conciliar interesses divergentes, ea própria dinâmica que os novos participantes foram conferindo ao GT , ao longo dos seus 14 anos de existência, tratou de adequá-la aos imperativos da realidade, muito embora não setenha feito nenhuma outra sistematização formal dessas novas diretrizes.

$\checkmark$ ale ressaltar que o grupo, desde o início, foi receptivo à participação de pesquisadores de outros países. T al abertura veio a ser ampliada na medida em que o grupo de estudos sobre a América-Latina não se consolidou, e as temáticas pertinentes passaram a fazer parte da pauta da Anped. N esse contexto, houve a mudança de sua denominação para "Estado e Política Educacional", proposta aprovada na assembléia de 1995, como meio de abrigar investigações que não tratassem apenas da realidade brasileira.

\section{O GT no contexto da Anped}

U ma das condições para que um GT da Anped tenha vida é a existência de demanda por parte de pesquisadores para apresentação de trabalhos nas reuniões anuais. Esta demanda pode ser tomada como indicativa da presença de vitalidade da área temática em questão, na medida em que sugere que investigações sobre ela estão em desenvolvimento e que há interesse em compartilhar seus resultados num fórum de discussão nacional. Q uando abordada por este ângulo, é destacável a dinâmica do GT "Estado e Política Educacional", no período aqui considerado.

Com efeito, os dados disponíveis sugerem que a inscrição de trabal hos para apresentação vem se mantendo acima da média das inscrições realizadas, o que o faz situar-se entre os cinco primeiros mais procurados da Associação (Q uadro 1). Essa procura permite que seja tecida e alimentada a relação com um conjunto de instituições a que pertencem os pesquisadores, possibilitando, dentre outras coisas, as condições para que seu núcleo básico exista e sobreviva de modo contínuo, bem como seu próprio funcionamento a cada reunião. 


\section{Quadro 1}

Q uantidade de trabalhos submetidos para apresentação nas reuniões anuais da Anped, por G rupo de Trabalho e de Estudo ${ }^{1}$ (1996 a 2000)

\begin{tabular}{|c|c|c|c|c|c|}
\hline GRUPO & & & $\mathrm{ANO}$ & & \\
\hline DE TRABALHO & $1996^{2}$ & $1997^{2}$ & $1998^{3}$ & $1999^{3}$ & $2000^{3}$ \\
\hline H istória da Educação & 38 & 39 & 32 & 50 & 43 \\
\hline M ovimentos Sociais e E ducação & 39 & 26 & 23 & 25 & 20 \\
\hline D idática & 34 & 42 & 21 & 42 & 32 \\
\hline Estado e Política E ducacional & 43 & 34 & 34 & 46 & 39 \\
\hline Educação Popular & 31 & 21 & 28 & 20 & 24 \\
\hline Educação da Criança de 0 a 6 anos & 45 & 30 & 35 & 30 & 37 \\
\hline Formação de Professores & 63 & 83 & 58 & 96 & 55 \\
\hline Trabalho e Educação & 42 & 28 & 30 & 28 & 26 \\
\hline Alfabetização, Leitura e Escrita & 49 & 29 & 29 & 41 & 29 \\
\hline Política de Ensino Superior & 30 & 21 & 24 & 21 & 23 \\
\hline Currículo & 36 & 29 & 23 & 29 & 30 \\
\hline Ensino Fundamental & 45 & 33 & 25 & 37 & 29 \\
\hline Sociologia da Educação & 20 & 16 & 24 & 25 & 20 \\
\hline Educação Especial & 25 & 30 & 21 & 38 & 36 \\
\hline Educação e Comunicação & 31 & 26 & 33 & 37 & 48 \\
\hline Filosofia da E ducação & 36 & 41 & 20 & 35 & 16 \\
\hline DE EST UDO & & & & & \\
\hline Educação de Pessoas J ovens e Adultas & - & - & 19 & 34 & 27 \\
\hline Educação M atemática & - & - & 15 & 30 & 40 \\
\hline Psicologia da Educação & - & - & 28 & 64 & 54 \\
\hline Total & 607 & 528 & 523 & 748 & 625 \\
\hline
\end{tabular}

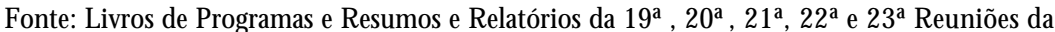
Anped.

${ }^{1}$ G rupo de Estudo é o caminho inicial para a constituição de um Grupo de T rabal ho e forma-se a partir da demanda de pesquisadores de uma determinada temática, permanecendo como tal durante dois anos, para que seja comprovada a sua capacidade de institucionalização como um GT .

${ }^{2}$ Inclui T rabalhos, Comunicações e Pôsteres.

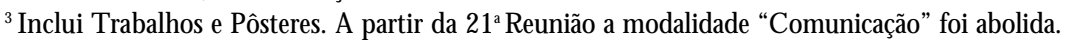


Segundo os dados analisados, verificamos que, nas últimas sete reuniões anuais (de 1993 a 2000), participaram do GT pesquisadores pertencentes a 60 instituiç̧̃̃es, ao considerarmos o conjunto dasatividades desenvolvidas: apresentação de trabalhos, comunicação e pôsteres selecionados pelo comitê científico - apresentação de trabal hos encomendados - , além da participação em sessões especiais promovidas com outros grupos de trabalho da Anped. N este total, têm destaque as universidades públicas estaduais e federais, mas é também significativa a presença das universidades católicas. D entre as demais, incluem-se as universidades privadas, institutos de pesquisa, O N G 's do campo educacional, secretarias estaduais e municipais de educação e instituições de outros países.

Em relação a essas últimas, é a partir de 1996 que identificamos uma abertura para a participação de pesquisadores de universi dades européias e, principalmente, latino-americanas, o que é compreensível em face das preocupações comuns com as reformas operadas nos sistemas educativos do continente a que pertence o Brasil. N este caso, tem sido forte a presença de argentinos, vindo em seguida a de uruguaios.

Por outra parte, ao termos em conta o papel de legitimação que a Anped exerce em relação à produção científica do campo, não é estranho que o GT tenha abrigado, no período em estudo, pesquisadores de instituições local izadas nas cinco regiões que compõem o País, espal hadas por 18 estados da federação. Têm, todavia, constituído o "núcleo duro" do GT as U niversidades: de São Paulo (USP); Federal de Pernambuco (U FPE); N acional deBraślia (U nB); Federal Fluminense (UFF); Federal de M inas Gerais (UFM G); Federal de Goiás (UFG); Federal do Rio Grande do Sul (UFRGS); Estadual de São Paulo (U nesp); Federal do Espírito Santo (UFES); Federal deM ato G rosso do Sul (UFM S); F ederal do Amazonas (UA); F ederal de Juiz deFora (UFJF); F ederal do M aranhão (U FM A) e Federal do C eará (U FC). I sso ao estarmos levando em conta a perenidade de apresentação de trabalhos, produzidos por pesquisadores destas instituições, nas reuniões anuais da Anped.

D e um modo geral, constatamos que são as universidades públicas, particularmente por meio de seus Programas de Pós-G raduação em Educação, o locus principal da produção do conhecimento sobre a temática "Estado e Política Educacional" que vem sendo discutida na Anped. Tal constatação vem ratificar resultados de estudos sobre outros campos do conhecimento, que também constatam a importância dessas instituições na produção do conhecimento científico no Brasil. ${ }^{7}$ 
Características e ten dências das investigações sobrea política educacional no Brasil

A abrangência peculiar à área temática conduz, necessariamente, a uma dispersão em termos de objetos e questões que aparecem como fulcro de investigações nos trabalhos analisados. Se, por um lado, esta condição deixa aberta a possi bilidade de um debate amplo e rico sobre os mais diversos aspectos da política educacional, por outro, não suscita induções no sentido de se procurar um maior aprofundamento de determinados temas que permitam um desenvolvimento teórico do objeto, aliado ao domínio e à compreensão das dimensões mais instigantes da realidade.

Essa dispersão manifestou-se nas dificuldades enfrentadas para classificarmos os trabalhos segundo eixos temáticos. Chegamos, entretanto, a um conjunto de subtemas, que deve ser entendido como uma estratégia de exposição da situação encontrada (ou uma das sínteses possíveis da realidade), contendo, todavia, os riscos que qualquer tentativa de categorização comporta.

O bservamos a existência de uma polarização em torno de dois agrupamentos de subtemas que, em conjunto, compreendem mais de $50 \%$ do total dostrabalhos discutidos no período. Além disso, são subtemáticas presentes na quase totalidade das reuniões.

Compõem o primeiro subtema: "Crise e R eforma do Estado, N ovos Padrões T ecnológicos, N eoliberalismo e a Política Educacional" trabalhos em que identificamos explícitas preocupações com os novos padrões assumidos pela regulação do Estado, secundadas, direta ou indiretamente, pelo trato do conceito de "neoliberalismo". N estes contextos, o "neoliberalismo" é acionado como uma referência com a qual se procura apreender a política a partir do enfoque da filosofia de ação que orienta as políticas econômicas, a ação do Estado e as reformas educacionais. A maior parte dos estudos caracteriza-se por ter a forma de ensaios oriundos de pesquisa bibliográfica, evidenciando a intenção de sistematizar histórica e teoricamente a questão, que aparece abordada de múltiplas maneiras.

D entre outras situações, verificamos uma recorrência na busca da sistematização de um conhecimento, no sentido de se estabelecer a contraposição entre a regulação estatal nos moldes keynesianos (com resgate das características do Estado do Bem-Estar), as especificidades da política educacional no Brasil, e o novo formato da ação do Estado, segundo os 
pressupostos neoliberais e os requerimentos do sistema produtivo. É neste mesmo agrupamento que podemos situar a maior parte dos estudos que tratam da realidade de outros países, em particular dosque abordam as políticas educativas da Argentina e do U ruguai.

Por outra parte, no conjunto dessa subtemática, pudemos identificar duas tendências. A primeira é a que se volta para a abordagem de questões como: "as propostas de reforma educacional no contexto da crise do Estado e dos novos arranjos internacionais"; " o ‘Estado M ínimo', o mercado e a privatização da educação"; "as transformações produtivas, competitividade, qualidade total, qualidade na educação, cidadania e 'cidadãocliente'"; "transformações produtivas e as repercussões nas propostas e medidas de política educacional"; "reforma do Estado, terceirização, descentralização e as restrições no financiamento da educação".

$\mathrm{N}$ o que se refere às abordagens teóricas que secundam essa primeira tendência, podemos afirmar da prevalência do marxismo em suas distintas vertentes. Entretanto, é mais recorrente a vertente que faz a leitura das políticas educativas como uma decorrência da "lógica do capital". N esse contexto, apesar da presença de estudos com uma consistência teórica no emprego de conceitos e categorias, são também encontrados os que as usam muito mais como um recurso para fazer denúncias, do que como uma estratégia analítica adequada.

A segunda tendência diz respeito, de um lado, às tentativas de sugerir a adoção de enfoques teóricos pouco usados no campo educacional, para que sejam iluminados os objetos, a exemplo das teorias da complexidade, com base em Edgar $M$ orin, $M$ ichel $M$ affesoli e outros, e dasteorias. crítica da evolução social e da ação comunicativa de Jürgen $\mathrm{H}$ abermas. $\mathrm{N}$ estes casos, têm-se ensaios que buscam dissecar as teorias, tendo 0 planejamento e as políticas educativas como referências. D e outro lado, foram encontrados trabalhos cujo objeto é a própria investigação dos principais conceitos que estão na cena das políticas educativas: o público e o privado na educação; a municipalização do ensino; a concepção liberal sobre a educação; a educação e a democracia; a desqualificação social e a exclusão; o novo paradigma do conhecimento e a educação; a qualidade na educação; a centralização e a descentralização da educação; dentre outros. Aqui predomina a reconstrução histórica do emprego dos conceitos no Brasil, como um meio de demonstrar o modo de sua apropriação pelo discurso governamental, quando justifica a definição e implementação de programas e projetos educativos na atualidade. Todavia, são também encontrados trabalhos cujo fulcro é uma problematização teóricoconceitual na perspectiva da sua utilização nas práticas investigativas. 
$\mathrm{N}$ ão podemosdeixar de considerar que as especificidades da própria área temática implicam o enfrentamento de questões teórico-práticas relativas ao Estado, o que impõe a necessidade de se acionar teorias que permitam entendêlo, eque possi bilitem um desdobramento conceitual sobre a dominação, o poder, as regras da representação política, os processos participativos, a democracia, a cidadania, dentre outros conceitos afetos ao campo investigativo, nas tentativas de compreensão dos processos que engendram as decisões educacionais, em articulação com outras políticas estatais e com o contexto social mais amplo no qual elas vão incidir. D esta perspectiva, é evidente o esforço dos pesquisadores no sentido da apreensão dos novos contornos que têm influenciado as decisões, bem como as tentativas de aprofundar os pressupostos teóricos com os quais ol ham o seu objeto.

$\mathrm{N}$ ão obstante, com exceções, os trabalhos revelam fragilidades no que concerne a um tratamento da dimensão interdisciplinar própria do objeto, e pouco adentramento nas discussões a respeito da crise de paradigmas, já amplamente problematizada pelos campos do conhecimento quealimentam as C iências da Educação. N esse sentido, ainda ébastante frágil a busca de uma compreensão mais aprofundada das atuais formas efunções do Estado, ou da incorporação/problematização de novos conceitos, como o da "sociedade em rede", de M anuel C astells, "Estado competidor", de Philip Cerney, "Estado avaliador", de Guy N eave (Afonso, 2000), ou mesmo das tentativas empreendidas por Boaventura de Souza Santos, quando ressignifica o terceiro setor para além da concepção neoliberal, invocando a reconstrução do espaço público e apontando para a "reinvenção solidária e participativa do Estado" (Santos, 1998).

O s Estudos sobre Políticas e Programas Governamentais representam a subtemática que vem congregando a mai or quantidadedetrabal hos do período em enfoque. $\mathrm{N}$ ela estão englobadas investigações sobre definições gerais da política educacional da U nião, estados e municípios, como também as que se voltam para programas e projetos específicos de cada uma destas esferas administrativas.

N este agrupamento, há estudos que investigaram a política educacional definida em nível do poder central, em conjunturas distintas, e que produziram contribuições significativas para a área, no que se refere à minuciosa análise documental contextualizada, pondo à disposição do campo uma competente sistematização dos processos de decisão, mas são poucos. T ambém são poucosos quese voltam para a análisede políticas nacionais específicas. N estes casos, tem-se apenas cinco trabalhos no período pesqui sado, entre os quais se destacam "As políticas de educação 
da U nião para a educação de jovens e adultos ao longo dos últimos governos", "Estado e a política de formação de magistério", "A proposição de diretrizes nacionais para o ensino médio: D ogma e liturgia" e "M udanças no mundo do trabalho e reforma curricular dos cursos de graduação no Brasil". São estudos com diferentes níveis de aprofundamento de suas temáticas. U ns apresentam um tratamento mais aprofundado das questões teóricas em articulação com as análises empíricas e outros sistematizam a legislação e a documentação pertinentes. Em comum, contudo, têm uma abordagem consistente das questões trabalhadas.

A tônica, entretanto, das investigações agrupadas na categoria "Estudos sobre programas e políticas de governo" é, sobretudo, a focalização de novas experiências na condução da política educacional, ou na implementação de programas e projetos, em estados federados ou em seus municípios. E éneste subconjunto que observamos um amplo recorte e fragmentação de objetos, o que impossibilita afirmar a presença contínua ea consistência de conhecimentos produzidos sobre a área, que permitam vislumbrar questões analíticas comuns e essenciais para a consolidação deste campo do saber.

Em face dessa realidade, é importante levarmos em conta que é bastante recente a legiti mação da área em destaque como campo investigativo, sobretudo no que respeita a abordagem da educação no contexto das políticas públicas. Um exemplo disso foi a tardia constituição do grupo de trabalho "Estado e política educacional", conformejá demonstrado. D a mesma maneira, é só em 1995 que a Associação N acional de Política eAdministração daE ducação (Anpae) institucionaliza este campo como integrante da esfera das suas preocupações.

Entretanto, essa densidade expressa uma forte característica dos trabalhos: a preocupação com a avaliação de programas e projetos específicos, tendência detectada em estudo anterior (Aguiar \& Azevedo, 1993) e que continua fortalecida.

D e um lado, isso espelha o enraizamento do GT em diversos estados da federação no exercício do papel de articulador e socializador nacional, de uma produção que analisa diferentes iniciativas forjadas a partir de especificidades locais. D e outro, a maior autonomia conferida aos estados e municípios desde a vigência da nova C onstituição do Brasil (a partir de 1988), aliada às medidas de descentralização de programas e das tentativas de maior democratização da gestão educacional incentada por governos locais, constituem o móvel para que as mesmas se tornem temas e objetos de investigação na nossa área temática, nas tentativas de captar e avaliar os alcances e os limites dessas mudanças. 
O bservamos neste agrupamento a forte presença de preocupações com a questão da democratização da gestão dos sistemas de ensino e das unidades escolares, como também com o impacto de diretrizes emedidas proclamadas como meios de melhoria da qualidade do ensino. Análise das repercussões de eleições diretas de diretores de escolas, da participação popular e dos conselhos escolares no controle social das políticas locais constituem também preocupações recorrentes.

Encontramos, ainda, nestes trabal hos, construções argumentativas que privilegiam a denúncia dos efeitos nefastos das orientações neoliberais para a vida dos professores, dos al unos e da escola. Embora politicamente importantes, pouco acrescentam em termos da percepção das mediações e dos conflitos subjacentes a estas práticas, a partir do emprego de referenciais analíticos mais consistentes, na perspectiva mesma de se colocar 0 conhecimento produzido como um instrumento para a mudança. U ma outra tendência identificada diz respeito a estudos que, embora ricos em termos de apresentação de dados, pecam pela profunda empiria.

Contudo, há também abordagens inovadoras, como as presentes nos estudos "G estão e organização do trabal ho na escola pública: Práticas sociais em educação em M inas G erais" e "A cultura organizacional e 0 impacto das propostas de mudança em escolas estaduais deM inas G erais". No primeiro, é utilizada a cultura organizacional como a principal ferramenta analítica, construída a partir de referências de uma abordagem pluralista que considera as múltiplas dimensões do real presentes na escola, tomada na qualidade de uma instituição social. D esta perspectiva, privilegia-se o modo de concretização de um programa no cotidiano de três escolas, focalizando a política educacional no espaço primeiro a que se destina. 0 segundo trabal ho tem por objeto a organização dos processos de trabalho na escola, analisados a partir de referências construídas criativamente, por meio de uma adaptação de categorias analíticas de M ichel Foucault e M ax W eber. É também destacável o estudo intitulado "Limites à Educação Básica, expansão do atendimento e relação federativa: 0 caso de M inas Gerais", tanto pela densidade analítica, quanto pela riqueza dos dados apresentados.

Aliás, dentre os estados federados, $M$ inas $G$ erais teve o maior número de investigações de sua política educacional. Com efeito, dos 15 trabal hos que se ocuparam de políticas e projetos de governos estaduais, oito, correspondentes a $53 \%$ deste total, focalizaram M inas G erais, o que se compreende, dentre outros aspectos, por seu pioneirismo na implantação do programa da qualidade total em sua rede escolar, o PróQ ualidade, com financiamentos do Banco M undial. N este conjunto, 
são múltiplos os aspectos abordados. O s estudos variam desde a análise documental das diretrizes de política, até o estudo de caso da escola pela qual começou o programa.

$\mathrm{N}$ o que concerne aos trabal hos que privilegiam a dimensão municipal das políticas (num total de oito), três deles se ocupam de inovações introduzidas por municípios governados pelo Partido dos T rabal hadores, dos quais dois pecam pelas análises apologéticas que também contribuem pouco para se avançar no conhecimento. Entre os demais é destacada a articulação entre município, Estado e U nião na oferta do ensino fundamental, a gestão democrática do ensino e o próprio processo de municipalização deste nível. A exemplo do que encontramos no agrupamento anterior, aqui também identificamos uma predominância de descrição de dados empíricos, com algumas exceções. Esteéo caso do estudo "Expansão e interiorização do ensino superior em Goiás nos anos 80: A política de privatização do público", que se baseia num referencial gramsciano para demonstrar como o processo de expansão deinstituiç̧ões do ensino superior em oito municípios goianos constituiu-se numa prática de privatização deste nível de ensino, com o concurso do poder local conservador.

U ma tercei ra subtemática em que os trabal hos foram classificados édenominada "Educação, legislação edireitos". N este contexto, se inserem investigações que têm como objeto a política educacional mediada pelas relações jurídico-políticas. M esmo que sua expressão numérica não seja significativa, trata-se de um subtema importante, particularmente ao considerarmos as contínuas alterações que vem sofrendo a ordem legal, como estratégia de legitimação das reformas educativas. Os estudos analisados tendem a se apoiar nas teorias do direito e abordam a questão de uma perspectiva histórica, ou se debruçam no exame da legislação recente e nos seus impactos para o campo educacional. D esta perspectiva, situaram-se análises sobre a Constituição de 1988, no que se refere ao novo pacto federativo em relação à descentralização da educação, bem como a respeito da efetividade dos novos mecanismos jurídicos na obtenção do direito ao ensino fundamental. D a mesma maneira, há análises a respeito da Lei de Diretrizes e Bases da Educação em termos de suas implicações para a "flexibilização" das práticas educativas e, ainda, a lei é tomada na condição de um referente para focal izar a legal idade das ações do Estado na educação. Q uase sem exceções, os trabalhos agrupados nesta temática são portadores de contribuições significativas para a compreensão da política educacional.

"Estudos sobre a participação da sociedade civil organizada na proposição de políticas" éa quarta subtemática. Entretanto, observamos 
um refluxo das investigações pertinentes, que tiveram vida em trabalhos apresentados nos anos de 1994 e 1995. M esmo que tenhamos anali sado apenas os seus resumos, eles indicaram a presença de uma abordagem importante para o entendimento da influência de grupos organizados na definição de políticas que estão postas em prática na atualidade. D o mesmo modo, são também poucos os estudos sobre o financiamento da educação (precisamente quatro), com a diferença de que foram apresentados nas reuniões mais recentes. N este caso, situaram-se investigações sobre parcerias entre empresas e escolas, sobre o financiamento das universidades federais após a implantação do Plano Real, sobre recursosfinanceiros e custos em redes e escolas municipais e um estudo específico sobre o Fundo de M anutenção do Ensino Fundamental e de Valorização do M agistério, o Fundef.

N esse sentido, observamos quetanto o financiamento da educação, como as políticas de avaliação do ensino não têm sido temas priorizados pela agenda deinvestigação dospesquisadores, como também o desenvolvimento de estudos comparativos. Sobre a avaliação, nos anos considerados, só encontramos dois trabalhos de uma mesma pesquisadora. 0 primeiro foi apresentado no ano de 1993 e teve por tema a política de avaliação de resultados no ensino fundamental da rede pública de São Paulo. 0 segundo é do ano 2000, "A avaliação da Educação Básica entre dois modelos", que, ao analisar o "estado da arte", traz contribuições importantes no sentido de priorizar questões para uma agenda de investigação. Q uanto aos estudos comparativos, destacamos, no ano de 1999, o trabalho "Reforma do Ensino M édio: Lições que vêm da Espanha", pela propriedade com que a investigação foi realizada, em termos da sua consistência analítica e pelas instigantes questões que traz para a reflexão sobre a realidade brasileira. Final mente, salientamostambém os desafios postos pelo trabalho "M apeamento das possibilidades de investigação da política educacional gestada na América Latina", por conter, ele próprio, a problematização de uma agenda de questões para a realização de estudos comparativos.

\section{Considerações finais}

A análise realizada nos permite apontar características presentes nas pesquisas cujo campo investigativo é a Política Educacional. Com efeito, podemos afirmar a existência de um significativo acervo produzido nos sete anos aqui considerados. N esse sentido, os pesquisadores têm colocado à disposição da comunidade acadêmica uma gama diversificada 
de estudos, sobre os mais distintos temas e problemas. Essa diversidade, porém, é, ao mesmo tempo, um ponto forte e fraco do campo temático. $\mathrm{Se}$, de um lado, a quantidade de objetos empíricos expressa uma característica necessária a um campo em constituição, ela também é problemática, no que se refere ao refinamento de ferramentas analíticas que permitam uma melhor abordagem dos objetos teóricos e empíricos e de suas interrelações.

D essa perspectiva, o que desejamos enfatizar é que a heterogeneidade da produção tende a impossibilitar uma acumulação de conhecimentos que venha a expressar a presença de "um programa de pesquisa", a partir do qual a comunidade concernente, em estreita interação, possa desenvolver eaprimorar procedimentos teórico-metodológicos com maior grau de consistência e com melhor grau de delimitação.

$N$ essecontexto, não podemos esquecer a dimensão interdisciplinar que caracteriza as investigações do próprio campo da educação em seu conjunto, o que coloca a necessidade premente de uma apropriação, melhor delimitada e mais atualizada, das contribuições forjadas no campo das $\mathrm{Ciências} \mathrm{Sociais} \mathrm{e} \mathrm{H} \mathrm{umanas.} \mathrm{Como} \mathrm{chamamos} \mathrm{a} \mathrm{atenção} \mathrm{no} \mathrm{corpo}$ do texto, é imprescindível a atualização da categoria Estado, essencial à análise das políticas educativas. É importante, também, o uso de parâmetros e procedimentos próprios dos estudos de aval iação de políticas sociais, tendo em vista a grande quantidade de investigações que se propõe a realizar avaliação de programas e projetos educativos, desconhecendo essas contribuições.

Entretanto, no seu conjunto, as análises realizadas, mesmo tendo encontrado problemas, demonstram a existência de potencialidades que indicam um campo de investigação em construção e, portanto, ainda sem tradição, mas que conta com a Anped neste seu processo de fortalecimento, legitimação e institucionalização.

Recebido para publicação em abril de 2001.

\section{$\mathrm{N}$ otas}

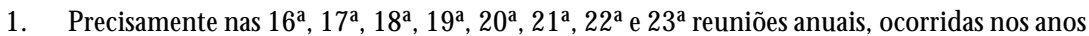
de 1993 a 2000.

2. Estamos nos referindo às normas de submissão dos trabalhos para a apresentação, à seleção preliminar dos mesmos pel os coordenadores dos GT 's e por pareceristas ad hoc eà seleção final feita pelo comitê científico da Anped. Os coordenadores são eleitos pelos pesquisadores do respectivo GT, para um mandato de dois anos, sendo facultada a eleição para um segundo 
mandato, o mesmo ocorrendo com os pareceristas ad hoc. D o mesmo modo, os membros de cada G T indicam os seus representantes para o comitêcientífico, que também é composto por um membro da diretoria da Anped. 0 mandato, neste caso, é de dois anos, sem possibilidade de renovação seqüenciada.

3. As análises dizem respeito aos resumos e textos integrais dos trabalhos e, portanto, não contemplam as modalidades "pôster" e "comunicação".

4. É oportuno esclarecer que só recentemente tem sido possível o acesso aos textos integrais dos trabal hos apresentados nas reuniões anuais da Anped. I sso só ocorreu na medida em que estes passaram a ser disponibilizados em CD -R om e por meio da publicação dos Anuários do GT em foco, fato que ocorreu justamente nos anos de 1999 e 2000.

5. O breve histórico aqui apresentado tem por base as informações registradas no I nformativo $\mathrm{n}$ 1, vol. 8, jan./mar. 1986, p. 2-8, no qual é reproduzido o debate "U ma conversa sobre grupos de trabal ho".

6. Foram os seguintes os GTs pioneiros: "Educação de 10 Grau", "Educação de 2ำ Grau", "Educação Superior", "Educação e Trabalho", "Educação Rural", "Educação e Linguagem" e "Educação do Préescolar".

7. Embora o tratamento da questão fuja aos objetivos do presente trabalho, não podemos deixar de registrar que esses resultados indicam os efeitos perversos da atual política para o ensino superior, na medida em que têm levado ao sucateamento das universidades públicas, impondo limites às práticas investigativas, o que trará conseqüências nefastas para o País.

\title{
KNOWLEDGE PRODUCTION ON THE EDUCATIONAL POLICIES in Brazil: The CASE ANPED
}

\begin{abstract}
ABST RACT: This paper presents the results of a research that analysed the features and trends of knowledge production on the educational policy in Brazil. Based on such empirical data as the production (papers) presented at the 'State and Education Policy W ork Group' of the $\mathrm{N}$ ational Association of Pos-Graduation and Research in Education (AN PEd) between 1993 and 2000, it assumes that both the legitimacy of this knowledge and its main trends result from a struggle between different theoretical perspectives and that the papers reveal effective relationships between researchers, social organization and the reality analyzed. The authors thus make a historical 'rescue' of the origins and trajectories of the State and Education Policy Work Group in order to present a qualitative and quantitative portrait of the thematic and subthematic topics which have prevailed during the studied period. They conclude discussing the reaches and limits of the institutionalization of this W ork Group and, consequently, of the field of knowledge on educational policy.
\end{abstract}

Key words: Educational policy; Brazil; Anped; State and educational policy work group; Knowledge production; Production review. 


\section{Referências bibliográficas}

AFO N SO, Almerindo J. "Reforma do Estado e políticas educacionais: Alguns tópicos para discussão." Anuário GT Estado e Política Educacional. Caxambu: Anped, 2000b.

AZEVED O, JaneteM .L. de. A Educação como política pública. Campinas: Autores Associados, 1997.

AZEVEDO, Janete M.L. de. \& AGUIAR, M árcia A. da S. Reflexões sobrea trajetória do G rupo deT rabalho Estado ePolíticaEducacional no Brasil. Boletim. Porto Alegre: Anped, out./dez. 1993b, no 2.

. "Políticas deE ducação. Concepçõese programas". In: W ittm an n, L.C. \& G RACINDO, R.V. (Coords.), 0 estado da arteem política egetão da educação no Brasil. 1991 a 1997. Braślia: Anpae/Inep, 1999.

BO U RD IEU, Pierre. M éthode Scientifique et $\mathrm{H}$ ierarchie des $\mathrm{O}$ bjects. Actes de la Recherche en Sciences Sociales, 1975, № 1.

. Le champ scientifique. Actes de la Recherche en Sciences Sociales, $\overline{1} \overline{9} 76, \mathrm{n} \cong 2 / 3$.

. 0 poder simbólico. Lisboa: Difel/Rio deJ aneiro: Bertrand Brasil, $1 \overline{9} 89$.

BRAN DÃO, Zaia \& BON AM IN O, Alícia C. "Posfácio". In: Brandão, Z. (O rg.), A crise dos paradigmas e a educação. São Paulo: Cortez, 1994.

FIGUEIRED 0, M arcos Faria \& FIGUEIRED O, Argelina M.C. Avaliação política e avaliação de políticas: U m quadro de referência teórica. Textos Idesp. São Paulo, 1986, no 15.

PAIVA, Vanilda P. "Pesquisa educacional e decisão política". In: W ARDE, M.J. ( ( rg.), N ovas políticas educacionais. C ríticas e perspectivas. São Paulo: PU C, Programa de Estudos Pós-G raduados em H istória e Filosofia da Educação, 1998.

RIC O, Elizabeth M elo ( 0 rg.). Avaliação de políticas sociais. U ma questão em debate. São Paulo: C ortez, 1998.

SAN T O S, Boaventura deS. Pela mão deAlice 0 social eo político na pósmodernidade. São Paulo: Cortez, 1995. 
. A reinvenção solidária e participativa do Estado. Seminário Internacional Sociedade e R eforma do Estado. Braślia: M are, 1998. (www.mare.gov.br).

. A critica da razão indolente. Contra o desperdício da experiência. São Paulo: Cortez, 2000.

\section{D ocumentos analisados}

An ped. Boletim Informativo. N iterói, maio 1984c, vol. 6, no 2 .

. Boletim Informativo. Niterói, jan./mar. 1986a, vol. 8, no 1.

. Boletim Informativo. N iterói, abr./jun. 1986b, vol. 8, no 2.

. 16 Reunião. Boletim; Programação; Resumo dos Trabalhos. Porto Alegre, 1993a, no 1.

. 16a Reunião Anual. Relatório, Boletim. Porto Alegre, 1993b, noํ․ 2 .

. 17ạ R eunião Anual. Boletim; Programação; Resumo dos T rabaThos. Porto Alegre, 1994a, no 1. กํㅡ 2 .

. 17 $7^{\mathrm{a}}$ Reunião Anual. Relatório. Boletim. Porto Alegre, 1994b,

.18 Reunião Anual. Boletim; Programação; Resumo dosT rabalhos e Comunicações. Belo H orizonte, 1995a, № 1. noํ․ 2 .

. 18 Reunião Anual. Relatório, Boletim. Belo H orizonte, 1995b, . 19² Reunião Anual. Programação. São Paulo, 1996a. . 19² Reunião Anual. Relatório. São Paulo, 1996b. . 20 Reunião Anual. Programa e Resumos. São Paulo, 1997a. . 20³ Reunião Anual. Relatório. São Paulo, 1997b. . 21ํㅡㄹ Reunião Anual. Programa e Resumos. São Paulo, 1998a. . 21a Reunião Anual. Relatório. São Paulo, 1998b. . 22ª Reunião Anual. Programa e Resumos. São Paulo, 1999a. 
. 22ª Reunião Anual. Relatório. São Paulo, 1999b.

Anais do Grupo de Trabalho "Estado e Política Educacional".

$\overline{2} 2^{\mathfrak{a}}$ Reunião Anual. Caxambu, 1999 c.

.23a Reunião Anual. Programase Resumos. Rio deJ aneiro, 2000a.

. Anuário. G E Estado e Política E ducacional. C axambú, 2000b. 